\title{
Viability of Narrowing Global Marketing Strategies to the State Level: A Study of Domino's Glocal Strategies in Ahmedabad City
}

\author{
Sonal Gogri, Minouti Jani \\ Assistant Professor, Faculty of Business Administration, GLS University, \\ Research Scholar, B.K. School of Management, Gujarat University, Ahmedabad, India
}

\begin{abstract}
There was a time when people were attracted to consistent global products. However, this standard of same product could not build loyal customer base. Thus, global brands and MNC's started experimenting with customized brands for different culture of consumers. This combination of Global strategies with the tint of cultural strategies influenced locally, called upon for Glocal strategies. Brands like Pizza Hut, McDonalds and Dominos among others have used this strategy successfully. In this paper, Feasibility of Dominos latest Glocal strategy in Gujarat state, especially in Ahmedabad city has been studied. The study is mainly based on analysis of secondary data, case studies, ethnography and observation. The results of the study will be helpful to the marketers and strategic decision makers.
\end{abstract}

KEYWORDS: Glocal Strategies, QSR, Quick Service Restaurants, Marketing, Strategic marketing, Global strategies, culturally influenced strategies

\section{INTRODUCTION}

In today's era, the millennia are looking forward to consistent and global brand performances. There was an era, when globalization brought a breakthrough in the areas of International Business. However, the global giants feel that standardization of products do not connect with the culturally bound consumers. Hence, customization was given limelight as opposed to mass marketing communications. In this regard, there are many global brands who are taking the path of attracting and delighting culturally influenced local customers.

(Williams, 2015) Marketing is about relationships; it is not just about translating material, it is about understanding the local market as well and making sure the message resonates with them, not simply put in their local language.

This combination of global marketing integrating with local marketing, gives birth to the buzz word Glocal.

(Khondker, 2004) According to the dictionary meaning, the term "glocal" and the process noun "glocalization" are "formed by telescoping global and local to make a blend." Glocalization (a portmanteau of globalization and localization) is the "simultaneous occurrence of both universalizing and particularizing tendencies in contemporary social, political, and economic systems."

In simpler words, Glocal reflects or is characterized by both local and global considerations.

(Prakash \& Singh, 2011) The concept of glocalization is particularly important to the food industry because of the seamless challenges this industry faces due to the typical differences that exist in the food habits of people belonging to various regions/religions/cultures across the globe.

This research article attempts to study, that how global giants are tapping the culturally influenced local markets.
Few important elements for this strategy to be effective are: First, Culture is the central factor. Multiple levels influences and shape the nature and extent of organizational identity. Second, Global standards should not be compromised but leveraged. In a global market a product or service is more likely to succeed when it is customized for the locality or culture without compromising the global standards. Third, Globalization relates to the tailoring of globally available products and services to local markets.

(Luigi \& Simona, 2018) Phillip Kotler elaborated certain advantages of glocal marketing (Kotler, 2009), as follows:

$>$ If brands are customized as per their needs, then customers feel that the brand is significantly connected to them

Marketing activities take places at different levels including strategic (top), tactical (middle) and operative (bottom). It is expected that these three levels work in congruence of overall marketing activities.

$>$ Successful Brands have potential to gain larger market share.

(Luigi \& Simona, 2018) But even though for a while selling standardized products and services was a good strategy, the world evolved and customers stopped feeling a connection with the generic products and communications.

The article studies few famous cases who have adopted the Glocal strategies. The objective is to identify if the Dominos' recent Glocal strategy will be successful or not in the Ahmedabad market. For achieving the research objectives, the paper has attempted qualitative research methods like critically analyzing secondary data and case studies, nethnograpghy and observations. The study will be helpful to marketers and strategic decision makers to understand how global multinational brands are trying to adopt culturespecific differentiation strategies in order to target and attract mass-market. 


\section{WHY AHMEDABAD CITY OF GUJARAT?}

Unlike other regions of India, Gujarat has the considerable amount of people preferring hard-core vegetarian food. Plus, Ahmedabad is a location with a high density of Jain population. People of Gujarat whose roots are culturally strong and are observing religion strictly prefer to visit only those restaurants which serve pure vegetarian food. This becomes a strong reason for many global gaints to experiments with food influenced culturally local. A study by (Raja, 2018) states that, Gujarat has proven to be a market of mostly vegetarian customers.

(Unnithan, 2013) In Gujarat, global restaurant chains like Pizza Hut, Subway, Dominos, KFC and McDonalds are not just experimenting with vegetarian food but also offering Jain food.

However, Ahmedabad being the largest city of Gujarat and one of the developing cities of India, has the potential to attract lot of cosmopolitan crowd. This population prefer globally influenced brands rather than consuming locally influenced brands.

\section{INSIGHTS FROM SELECTED CASE STUDIES: SUBWAY}

(Demi \& Jonathan, 2015) Examines how Subway, the US fast food restaurant franchise, has adapted to Indian culture. Glocalization theory will be the guiding framework used in this analysis. Glocalization rests on the premise that a universal concept must change to fit and function in a local culture. Blending the local and the global, it provides a passage to empowerment where modifications to a particular commodity can make it prosper in various traditions. Four important themes of glocalization emerged from this analysis: (1) adjustment of restaurant ambience; (2) adoption of Jain values; (3) adjustment of advertising practices; and (4) adjustment of the use of social media. An important conclusion is that, although India is embracing modernity, Subway has honoured many religious and cultural views in that nation.

\section{AMUL}

(Rubdy, 2018) Looks at representative samples of multilingual billboard advertising with the aim of studying the dynamics of consumerist identity construction in relation to the English-knowing, middle-class Indian bilinguals they target.

The advertisement series of Amul strikes the balance between cultural elements and pragmatic and progressive thinking. The ads have a sarcastically humorous appeals striking right with culturally influenced glocal consumers.

\section{AMAZON}

To achieve competitive advantage over existing market leaders like Flipkart and emerging competitors like Snapdeal and Aliexpress, Amazon has adopted culture-specific branding strategy to attract its Indian leads.

(Yadav \& Mahim, 2018) This case study provides a detailed analysis of Amazon India's branding strategy by way of analyzing popular branding campaigns such as "Try to kar", "Aur Dikhao", "Kya Pehnu" and "Apni Dukaan" (As shown in Image 1)that enabled the global brand to reach to the masses of Tier-II and Tier-III cities in India. Amazon India strategizes to attract Indian consumers by rightly capturing their behavior in terms of demanding "highest power of options", "fashion choices", "originality" and "trust" with its local flavored advertisement campaigns enabling it to create a "trusted, reliable and local" brand identity.

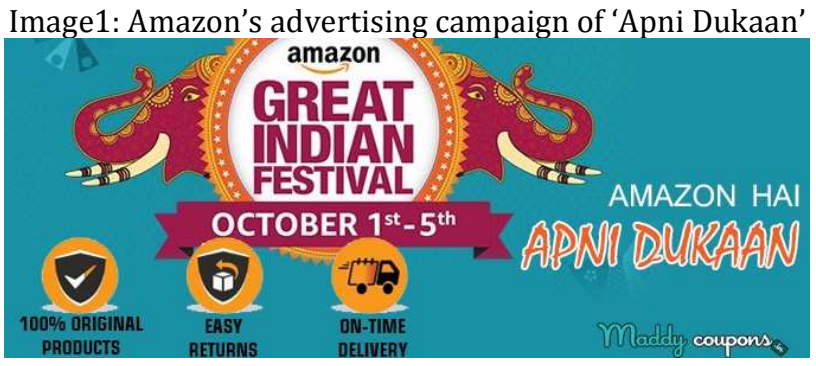

\section{PIZZA HUT}

Pizza Hut in India has introduced local flavours in their signature Italian pizzas. Pav Bhaji Pizza and Chhole Bhature are among their star dishes under glocal strategy. As shown in the Image 2, pizzahut offers Rawalpindi Channa pizza influenced by the Punjabi cuisine.

(Chauhan, 2016) Pizza Hut also has its first vegetarian restaurant in the world in Ahmedabad, India which also offers Jain food.

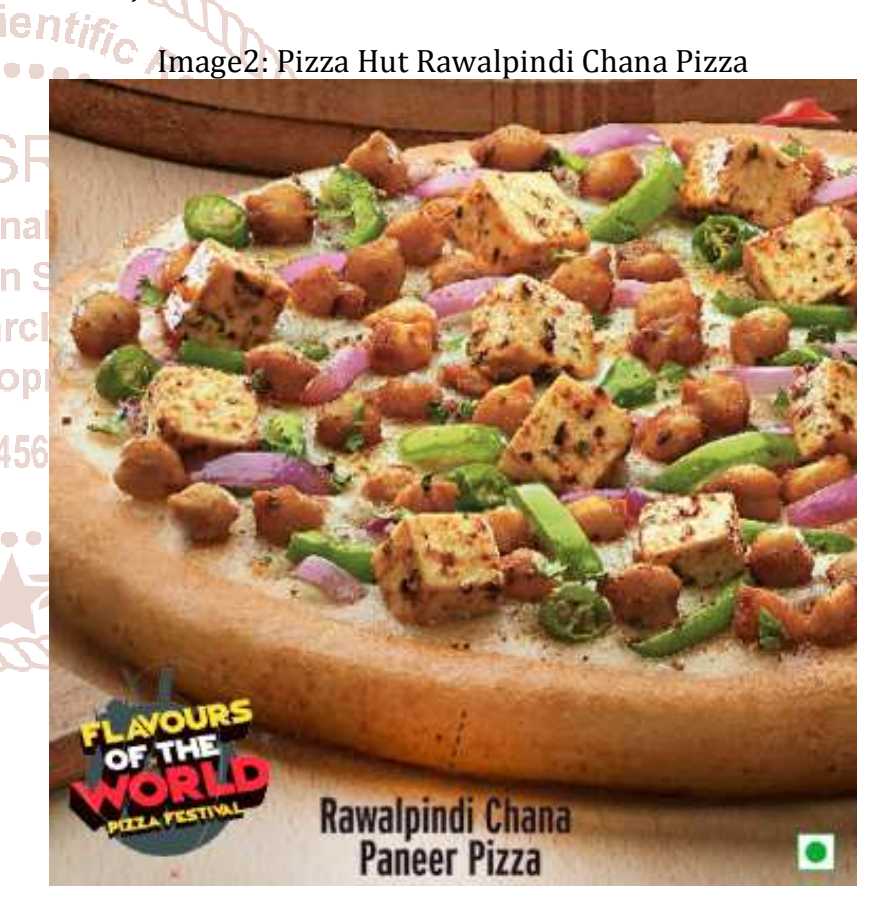

\section{DONALD'S}

When it comes to adopting glocal strategies giant food chain Mc Donald's too has left no stone unturned. It has embraced glocal strategies across countries.

(CASE, 2010) In the UK, McDonald's strategy is to listen more to local consumers and then act on it. The company strives to do this around the world. Some if its local favorites around the world include the McItaly burger in Italy, Maharaja Mac in India (As shown in Image 3), the McLobster in Canada, the Ebi Filit-0 in Japan.

(Luigi \& Simona, 2018) McDonald's, a globalization stereotype, has adapted its global marketing to different regions or countries. For instance, the fast-food chain has beer in its product range in Germany, wine in France, mutton pies in Australia and McSpaghetti in Philippines. Also, it 
provides Maharaja Mac and Veggie McNuggets in India, which is made of lamb or chicken; the McLobster in Canada and, in Japan, the Ebi Filit-0, a kind of shrimp burger, Teriyaki Burger in Japan / Malaysia, Burger served with rice in Indonesia / Philippines, Samurai Pork Burger in Thaildand, McLaks (grilled salmon) in Norway and McHuero (poached hamburger) in Uruguay.

Image3: McDonald's Maharaj Mac - The Social Burger

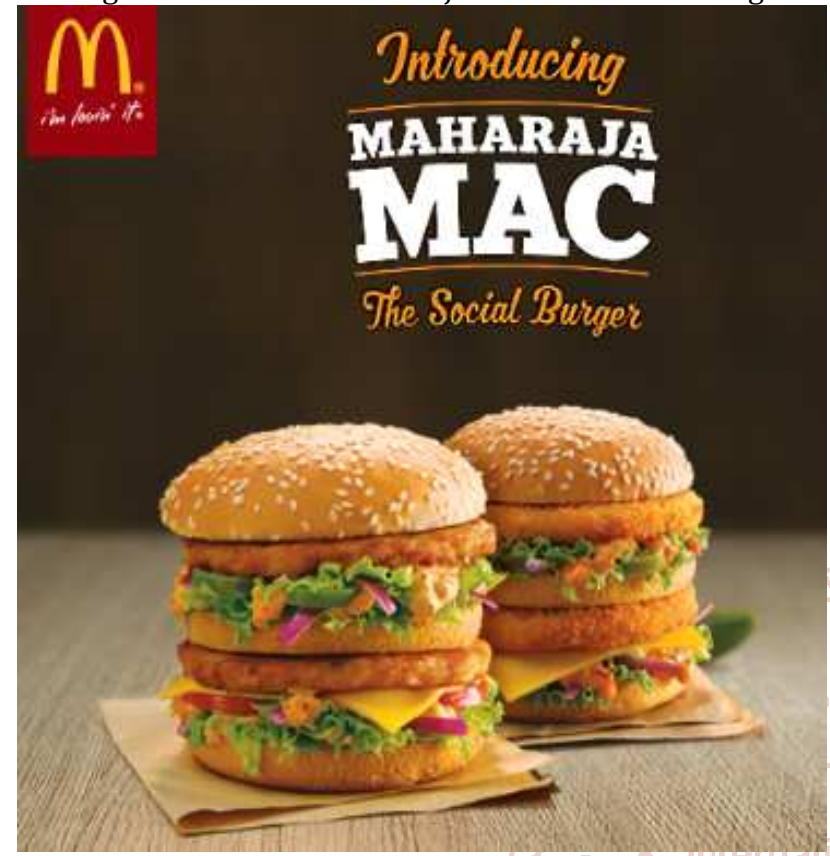

KFC

(CASE, 2010) KFC has a vegetarian thali (a mixed meal with rice and cooked vegetables) and Chana Snacker (burger with chickpeas) to cater to vegetarians in India

\section{DISNEY LAND}

Not just food chains, but the largest theme park brand Disneyland has also adopted glocal strategies.

(CASE, 2010) In 2005, Disneyland was not that successful in Hong Kong with park attendance and growth revenues. Disneyland then made an effort to cater to the local Chinese taste by reducing prices, adapting to local Chinese customs and labor practices and also changed the decors and settings. Glocalization was successfully applied to the theme park in Hong Kong.

\section{DOMINOS}

A glocal strategy standardizes certain core elements and localizes other elements. It is a compromise between global and domestic marketing strategies. Dominos has always been known to lure its culturally influenced local customers.

But this time in 2018, it has moved out of its comfort zone by declaring pure vegetarian pizzas in entire state of Gujarat. Since 2015, during Navratri festival the global food giant is known to serve only vegetarian pizzas in entire Gujarat, and in many outlets across the country (As shown in Image 4). The American giant had increase in sales during this festival, and hence decided to put up green dots across the state permanently (As shown in Image 5).

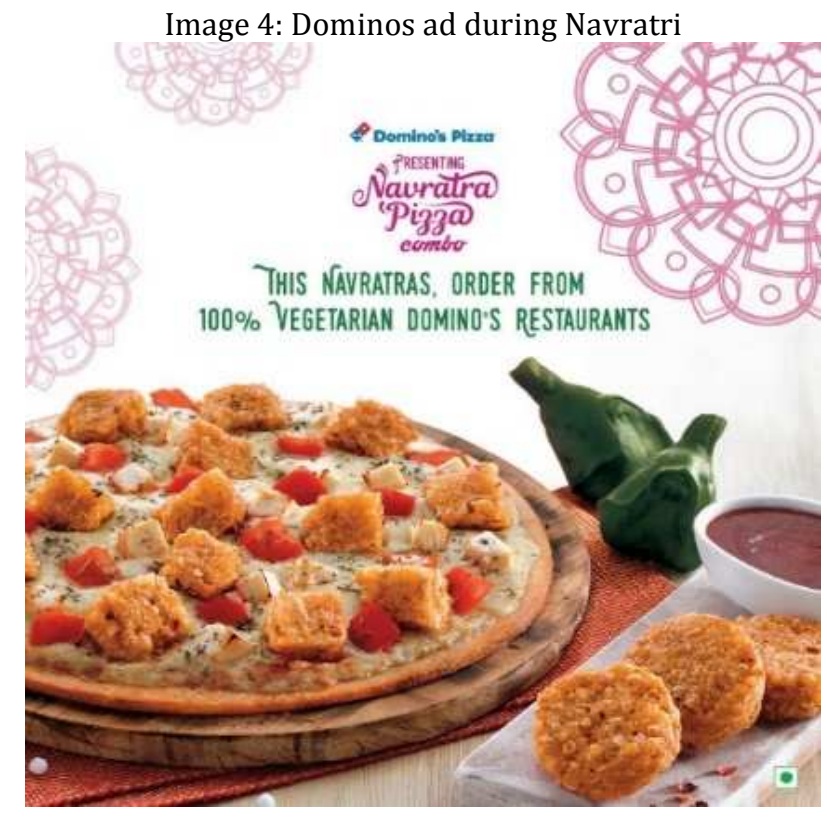

The decision to move pure-vegetarian was not overnight. It has been a well-thought of and a planned decision.

As per the study, (News-Artcile-Businessline, 2015) During Navratri 2015, It was the first initiative by any pizza chain that all there 164 restaurants will serve fully vegetarian menu. "We expect a 5-10\% growth in these restaurants. If we get a good response, we may continue to offer veg-only menu there even after Navratri," Ajay Kaul, CEO, Jubilant Foodworks, told BusinessLine on Wednesday.

(Chauhan, 2016) However, it was not the first time. In 2012, Subway opened its first all-vegetarian outlet on the campus of Lovely Professional University (LPU) in Jalandhar, Punjab.

The decision is based on customers' feedback and market research. The article identifies that, (News-ArtcileBusinessline, 2015) Earlier, Domino's Pizza had experimented with vegetarian-only restaurants locally for some time. "We got good response from our customers who thanked us for protecting their religious sentiments.

Image 5: Outdoor Hoarding of Dominos ad going 100\% vegetarian in Gujarat

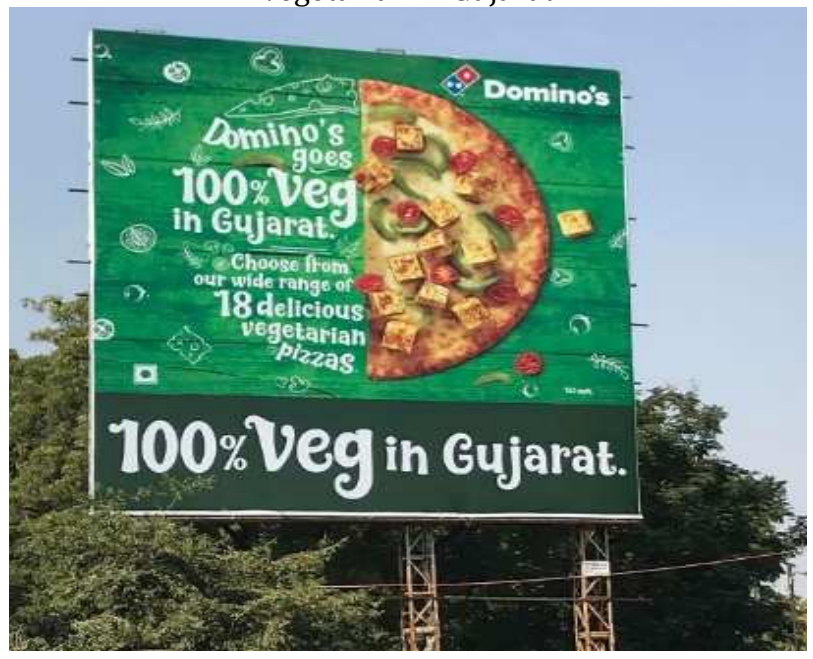


Nevertheless, Dominos has its own reasons for taking such a demanding decision.

As reported in (NEWS-ARTICLE, 2018), Domino's Pizza has cleared off non-vegetarian pizzas from its menus in Gujarat citing reasons that the state is a market where customers prefer to eat at restaurants that do not serve meat.

(News-Article-BusinessToday, 2018) Since Gujarat has come across as a market that prefers vegetarian restaurants, the decision was taken to take off all non-vegetarian offerings from the menu. Domino's has 75 outlets operating out of Gujarat, all of which have stopped taking orders for pizza with non-vegetarian toppings. The sole Domino's outlet in neighboring Daman, however, is still serving chicken-topped pies and other non-vegetarian offerings.

This is for the very first time that a global giant American pizza house has taken such a thought-provoking decision. The study of (News-Artcile-Businessline, 2015) shows that, Domino's Pizza is India's market leader in the chained pizza market with nearly 72\% market share (as per Euro Monitor Consumer Food Service Report, 2015).

Though Dominos can enjoy its first-mover advantage, but this Glocal strategy has many challenges.

A study by (Raja, 2018) states that, in several cities across Gujarat, the sudden decision of the outlet to go vegetarian has left the customers disappointed. In several cities across Gujarat, the sudden decision of the outlet to go vegetarian has left the customers disappointed, with most of them venting out on social media platforms. In a blog of (huffingtonpost), the author states that the anguished Domino's Customers take to Twitter over pizza chain going vegetarian in Gujarat.

Based on the article analysis, with reference to Dominos Glocal Strategy in Gujarat, the strengths and limitations of this strategy has been estimated.

\section{Strengths:}

$>$ Product innovation: culturally influenced flavors and ingredients in menu

$>$ Strong brand identity

$>$ Loyal customers by bonding with them culturally and emotionally

$>$ Increase in loyal customer base gradually decreases expenses on customer acquisition and retention.

\section{Limitations:}

$>$ Changing consumer habits, tastes and preferences

$>$ Intense competition in QSR (Quick Service Restaurants) category

$>$ Ahmedabad is one of the largest cities attracting metropolitan crowd. This non-vegetarian lovers may not welcome such initiative and hence may switch to competing brands.

$>$ Recently, many new restaurants in Ahmedabad have started offering authentic global flavors influenced by Japanese, European, French, Lebanese cuisines. Hence, in this trend, Dominos has taken a risk of making local strategy for consumers who aspire to live globally in their perceptions.

\section{CONCLUSION}

Glocal strategies are surely a way to reach consumers heart and share an emotional bond with them. The strategy of Dominos to offer pure vegetarian pizzas across Gujarat might be a wonderful idea, but adopting this strategy in Ahmedabad city may not prove to be fruitful in near future. Because of changing trends, habits, tastes and preferences of people in Ahmedabad, Dominos might have to rethink their plan in coming two-three years.

\section{REFERENCES}

[1] CASE. (2010, February). Glocalization Examples - Think Globally and Act Locally. Retrieved from http://www.casestudyinc.com/:

http://www.casestudyinc.com/glocalization-examplesthink-globally-and-act-locally

[2] Chauhan, D. (2016, March 8). Do You Know Which 4 Popular International Food Chains Went All-Vegetarian Only For India? Retrieved from www.scoopwhoop.com: https://www.scoopwhoop.com/First-All-VegetarianMcDonalds/\#.xjbj1qcpo

[3] Demi, S., \& Jonathan, M. (2015). Glocalization of Subway in India: How a US Giant Has Adapted in the Asian Subcontinent. Journal of Asian and African Studies.

[4] huffingtonpost. (n.d.). Retrieved from https://www.huffingtonpost.in/2018/10/11/anguishe d-dominos-customers-take-to-twitter-over-pizzachain-going-vegetarian-in-gujarat_a_23557839/

[5] Khondker, H. H. (2004). Glocalization as Globalization: Evolution of a Sociological Concept. Bangladesh $e$ Journal of Sociology. Volume 1. Number 2. July.

[6] Luigi, D., \& Simona, V. (2018). THE GLOCAL STRATEGY OF GLOBAL BRANDS. Studies in Business and Economics, 147-155.

[7] News-Artcile-Businessline. (2015, October 15). this navratri dominos spreads out all veggie menu. Retrieved from www.thehindubusinessline.com/: https://www.thehindubusinessline.com/companies/th is-navratri-dominos-spreads-out-allveggiemenu/article7762047.ece

[8] News-Article. (2018, October 10). DOMINOS IN GUJARAT. Retrieved from BusinessToday.in.

[9] NEWS-ARTICLE. (2018, October 10). Domino's outlets in Gujarat take non-vegetarian pizzas out of the menu. Retrieved from https://www.businesstoday.in/: https://www.businesstoday.in/latest/trends/dominos -outlets-in-gujarat-take-non-vegetarian-pizzas-out-ofthe-menu/story/284578.html

[10] News-Article-BusinessToday. (2018, October 10). DOMINOS IN GUJARAT. Retrieved from BusinessToday.in.

[11] NEWS-ARTICLE-BusinessToday. (2018, October 10). Domino's outlets in Gujarat take non-vegetarian pizzas out of the menu. Retrieved from https://www.businesstoday.in/:

https://www.businesstoday.in/latest/trends/dominos -outlets-in-gujarat-take-non-vegetarian-pizzas-out-ofthe-menu/story/284578.html 
International Journal of Trend in Scientific Research and Development (IJTSRD) @ www.ijtsrd.com eISSN: 2456-6470

[12] Prakash , D., \& Singh, D. (2011). GLOCALIZATION IN FOOD BUSINESS: STRATEGIES OF ADAPTATION TO LOCAL NEEDS AND DEMANDS. Asian Journal of Technology \& Management Research, Vol. 01 - Issue: 01 (Jan - Jun).

[13] Raja, A. (2018, October 9). Domino's 'only vegetarian' menu before Navratri, now a permanent fixture, Vadodara. Retrieved from Indianexpress.com: Domino's 'only vegetarian' menu before Navratri, now a permanent fixture

[14] Rubdy, R. (2018). Code Alternation and Entextualization in Bilingual Advertising: The Construction of Glocal Identities in India's Amul Butter Ads. Language and Literature in a Glocal World, pp 2956.
[15] Unnithan, C. (2013, March 6). US food giants turn vegetarian in Gujarat . Retrieved from /timesofindia.indiatimes.com/:

https://timesofindia.indiatimes.com/city/ahmedabad/ US-food-giants-turn-vegetarian-inGujarat/articleshow/18823980.cms

[16] Williams, A. (2015, September). Going glocal: How global brands can meet local customer promises. Retrieved from https://www.cmo.com.au/: https://www.cmo.com.au/article/583986/goingglocal-how-global-brands-can-meet-local-customerpromises /

[17] Yadav, N., \& Mahim, S. (2018). Amazon India's "Apni Dukaan": branding strategy. Emerald Emerging Markets Case Studies. 